\title{
14
}

\section{The 'Telos' as a Lens That Illuminates Values in Practice}

\author{
Nina Kurlberg
}

\section{Introduction}

The question at the heart of this chapter is, how can the perspective of institutional logics contribute to research on values in organisational practice? I address this question using empirical research conducted within an international faith-based development organisation (FBDO) in the UK. The argument advanced is that it is the 'telos' of each institutional logic in action within the organisation - that is, its ultimate aim or intention-that shapes the values in operation within organisational practice. While all institutional logics are value-based, some are more explicitly so than others. By identifying the teloi (plural of telos) of the institutional logics dominant within organisational practice, the values tacit within it are brought to light. Thus, the chapter both illustrates the contribution the institutional logics perspective can make to research on values in practice and provides insight into how these values 'align with

\footnotetext{
N. Kurlberg $(\bowtie)$

University of Edinburgh, Edinburgh, UK

e-mail: nkurlber@ed.ac.uk 
the telos and overall goals inherent to practices' (Askeland et al., 2020, p. 3).

I begin by outlining the theoretical framing for the chapter, which introduces both the institutional logics perspective and the place of values within this. In this section I also explain the relationship between teloi and values. I then provide a brief overview of how the institutional logics in action within organisational practice can be 'captured' using a 'pattern-matching technique' (Reay \& Jones, 2016), drawing on my empirical research. Finally, I use this research to demonstrate the importance of the category 'telos' for research on values in practice.

\section{Theoretical Framing}

\section{Institutional Logics: A Brief Overview}

The concept of institutional logics first emerged as a metatheoretical perspective through Friedland and Alford's 1991 critique of organisational and neoinstitutional theory on account of its failure to take societal context into consideration. According to Friedland and Alford (1991, p. 232), essential to any understanding of individual and organisational behaviour is an understanding of the societal context in which such behaviour occurs. They conceive of society as an interinstitutional system (1991, p. 240), and the institutions of which it is comprised as both 'supraorganizational patterns of activity' that shape human behaviour and symbolic systems that enable individuals and organisations to order and give meaning to this behaviour (1991, p. 232). Institutions can also be described as 'the rules of the game' in any given society (North, 1990, p. 3), with these rules incorporating both 'formal' and 'informal' components - the former typically relating to clearly articulated 'written' rules, and the latter, to unspoken social conventions and 'codes of conduct' (North, 1990, p. 4).

As such, institutions have both material and symbolic components, and further, there is a connection between institutions and action. Yet, while the behaviour of individuals and organisations is constrained by 
institutions, it is not determined by them (Friedland \& Alford, 1991, p. 256): although the agency of societal actors is embedded within societal institutions, these institutions are themselves socially constructed (Thornton \& Ocasio, 2008, p. 104), and societal actors play a key role in either reproducing or transforming them (Thornton et al., 2012, p. 80).

Fundamental to each institution is a logic that 'guides its organizing principles and provides social actors with vocabularies of motive and a sense of self' (Thornton \& Ocasio, 2008, p. 101), and it is this that is referred to as an institutional logic. Friedland and Alford hold that the influence of multiple institutional orders within organisations leads to conflict between their logics. This, because rationality is institutionspecific (1991, p. 235), or to put it differently, the practices that emerge within each institutional order are 'ontologically rational' (Friedland, 2009, p. 25).

Building on Friedland and Alford's pioneering work, Thornton et al. (2012) developed a method by which institutional logics can be analysed socio-scientifically. They produced a typology of the logics of what they perceive to be the seven institutional orders that comprise the interinstitutional system (i.e. society), identified as family, community, religion, state, market, profession, and corporation. They conceptualised the perspective as a matrix, placing the institutional orders along the $\mathrm{x}$-axis. Along the $y$-axis they placed the 'elemental categories, or building blocks, which represent the cultural symbols and material practices particular to [each] order' (2012, p. 54) — such as 'sources of authority', 'basis of norms', or 'informal control mechanisms' (see Table 14.1). In other words, for each institutional order, the content of these y-axis categories represents their logic.

It is important to note that the $y$-axis categories within Thornton et al.'s typology are not definitive and can be expanded upon or amended depending on context. However, specifying categories according to which institutional logics can be seen in action enables analysis of how they impact practice, as this chapter illustrates. Institutional logics are notoriously difficult to define, let alone identify, and therefore the benefit of Thornton et al.'s approach is that it enables one to analyse the way in which they can be seen in action. 


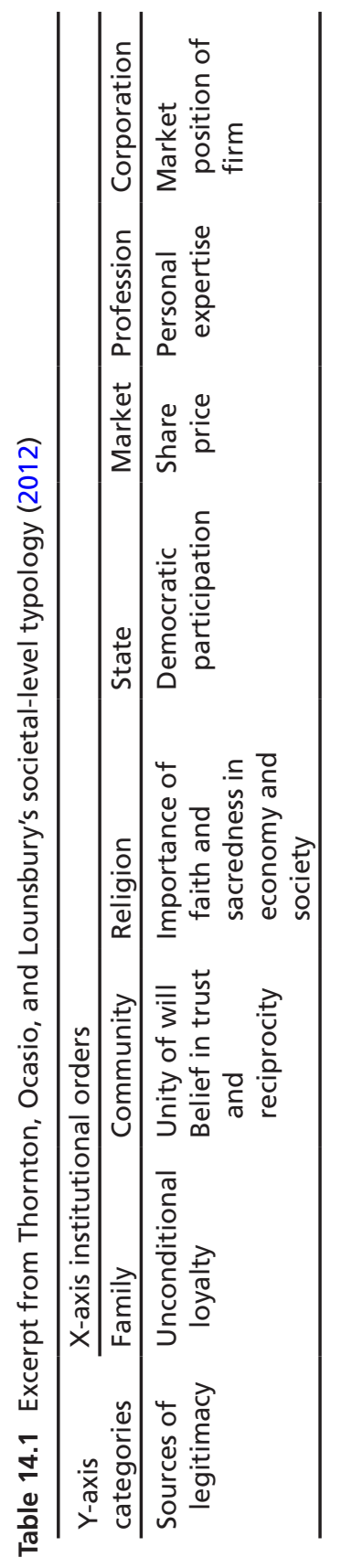




\section{Values and Institutional Logics}

What, then, is the connection between institutional logics and values? While Thornton et al. (2012, p. 44) argue that values are 'anchored' in societal-level institutional orders and thus embedded within institutional logics, values are largely absent from their approach, and consequently from much of the existing empirical research that has derived from it. Indeed, one of Friedland's critiques of their approach is on account of this 'most critical omission' (2012, p. 585). Nevertheless, values are arguably implicit within Thornton et al.'s approach. A key aspect of values on which there is general consensus within the literature is that they are 'conceptions of the desirable' (Kraatz et al., 2020, p. 478). Since Thornton et al. hold that institutional logics shape organisational actors' perceptions of what is desirable and appropriate, institutional logics can also be said to shape their values. Yet the question remains as to how the perspective can be applied to research these. In order to address such a question, it will be important to first explain precisely how values are understood within this chapter.

As Kraatz et al. (2020) highlight in their helpful overview of the literature on values within institutional scholarship — of which there is surprisingly little from recent years - values have a 'dynamic and processual aspect' (2020, p. 475), 'operate at multiple levels of society' (2020, p. 476), and bridge 'the (outwardly) separate worlds of social science and morality' (2020, p. 477). Thus, values are multifaceted and elusive and can be understood and defined in differing ways. Within this chapter, Askeland et al.'s (2020, p. 3) working definition of values is adopted; that is, values are individual and collective trans-situational conceptions of desirable behaviours, objectives and ideals that serve to guide or valuate practice'. Askeland et al. also underscore the connection between values and 'morality', highlighting the notion of 'realising the good' that is inherent within values. This aspect is particularly salient for the chapter given its focus on FBDOs and connects with another aspect of values highlighted within the literature - the recognition that they are somehow related to the 'ends', or goals, of action. 
The perspective of institutional logics brings an additional dimension to this understanding of values. As already noted, according to Thornton et al., values are anchored in institutional orders and therefore embedded within institutional logics. Friedland and Alford (1991, p. 235) hold that these orders also 'generate values' and, by extension, that values therefore anchor institutional logics. To put this in another way, institutional logics are value-based. Whereas some institutional scholars, such as Selznick, see a distinction between values and the 'less-ideal goals' embodied by organisational operative systems (Kraatz et al., 2020, p. 479), using the perspective of logics would lead one to argue that such systems are not valueless; rather, their values are tacit. Summarising Weber, whose theory of 'value spheres' aligns in a number of significant ways with the institutional logics perspective, Friedland (2013, p. 18) writes: 'As the claims for and the scope of religious ethical systems have been challenged and attenuated, we moderns fail to recognize that the "routines of everyday life" are likewise grounded in their respective "gods".' What Weber referred to as the 'gods' of value spheres, Friedland (2013, p. 18) has called 'institutional substances', that is, 'the unobservable, but essential, "value" anchoring an institutional logic'. There is an important connection between the 'institutional substance' or 'anchoring value' of a logic and its telos, and this will be discussed in the following section.

\section{The 'Telos' as a Category}

'Institutional substance' is a particularly important concept for Friedland, and in order to understand what is meant by this, it is vital to briefly outline the way he uses the term 'value'. Friedland understands 'value' as being more than a subjective valuation-values are also performative (2013, p. 21). He helpfully explains: '[v]alues must be both exteriorized as material practices that deploy objects, and interiorized as possessions that possess their practitioners' (2013, p. 20). Friedland goes on to note that '[i]nstitutional logics presuppose an immanent, internal relation between value and practice', and this is an important assumption underlying the perspective (2013, p. 20; see also 2017, p. 40). 
Returning to the concept of institutional substance or anchoring value, this has been developed in Friedland's recent work to include a more explicitly teleological element, which he envisions as being internally related to its ontological element. As Friedland explains, an institutional substance or anchoring value 'bounds the ontological and the teleological, its reality as well as its orienting quality, its goodness' (2018, p. 1371). The values in practice that are the focus of this chapter are rooted in the anchoring value.

Within my empirical research, the y-axis category that emerged as particularly important was that of 'telos' - that is, the ultimate aim or intention of the institutional logic. Given the expectation within the sector that organisations are organised around specific social 'causes', FBDOs are often very mission- or goal-focused. Thus, while Friedland's conceptualisation of the value anchoring each institutional logic is broader than the concept of 'telos', encompassing both teleological and ontological aspects as it does, 'telos' is a helpful category for analytical purposes given my research context due to its directional, goal-oriented dynamic. The telos of an institutional logic is in reality inseparable from its anchoring value, and while I agree with Friedland that teleology and ontology are internally related in this regard (2018, p. 1376), focusing solely on the 'telos' in analysis sheds light on the values in practice within an organisation since these are rooted in the anchoring value and therefore also intimately connected to and inseparable from the telos.

It became apparent through my empirical research that although all logics are value-based, some are more explicitly so than others. Therefore, as will be illustrated below, adding the category 'telos' to the typology of logics was a critical aspect of the research: by enabling the telos of each logic to be identified within the data, this also enabled tacit values to be identified. Before demonstrating how this can be done, I will briefly outline how institutional logics can be identified. 


\section{Capturing Institutional Logics in Action}

\section{Using the 'Pattern Matching Technique'}

In order to 'capture' the institutional logics in action within organisational practice in my empirical research, I used a 'pattern matching' technique (Reay \& Jones, 2016), which is an approach taken in a number of studies, such as Goodrick and Reay's (2011) research on pharmaceutical practice in the US. This technique 'requires researchers to first identify and explain the pattern of behaviors associated with the ideal type of a particular logic and then evaluate their data' against these ideal types (Reay \& Jones, 2016, p. 446). In comparison to the two alternative approaches to capturing institutional logics outlined by Reay and Jonesthat is, the 'pattern deducing' or 'pattern inducing' technique - the 'pattern matching' approach privileges both theory and previous research to construct 'ideal types' of the different institutional logics of interest to the research that then serve as the instrument through which empirical situations are interpreted (2016, p. 447).

Developed by Weber in the 1900s (e.g. see Weber, 1949), the ideal type' is a tool that can be used to assist analysis of social phenomena. It is neither descriptive nor analytical; rather, it is an 'abstraction from reality' (Goodrick \& Reay, 2011, p. 378), presenting 'ideal' behaviour that is not expected to occur (Gerhardt, 1994, p. 84). The purpose of so doing is to enable socio-scientific interpretation to hold in tension both broader, societal-level dynamics - represented by this behaviour-and the specificity of individual situations. The ideal type has the ability to do this because of the way that it is used in the research process; that is, whilst it is general in its construction, it is used as a point of reference against which the specific characteristics of individual situations can be compared and the differences accounted for. Swedberg (2018, pp. 188-9) notes that it is this stage of accounting for difference that enables one to analyse the particularity of the empirical situation.

Researchers wishing to employ the pattern matching technique to capture logics should first develop a typology of logics for their chosen field of research. In the following section I will illustrate how this can be done. 


\section{Constructing the Typology of Logics}

I carried out my empirical research in two stages: the first was to develop a field-level typology of the institutional logics in action within the field in which the FBDO I was researching operates. This approach was chosen since organisational- and field-level institutional logics are connected: ' $[o]$ rganizational fields and industries are viewed as having their own logics nested within societal level institutional orders' (Goodrick \& Reay, 2011, p. 375).

The field-level typology developed through my research is closely connected to Thornton et al.'s societal-level typology but relates to a narrower and more specific sphere of action. The definition of 'field' that I employ derives from institutional theory; that is, the field is a group of organisations 'that partakes of a common meaning system' and whose interaction and engagement is frequent and significantly shapes practice (Scott, 2008, p. 86). The first step in the process of constructing a fieldlevel typology of logics, then, is to identify an appropriate field, sampling frame, and method of data collection. Once these have been identified, the existing theory and literature can be used as the starting point to build the typology of logics by exploring their application within the specific field of interest, drawing on any data collected as necessary. It is important to remember during this stage of the process that institutional logics 'shape individual and organizational practices because they represent sets of expectations for social relations and behaviour' (Goodrick \& Reay, 2011, p. 375, emphasis added).

Within my own research I began with Thornton et al.'s ideal types and took an approach similar to that taken by Goodrick and Reay (2011, p. 378). The question underlying the typology's construction was, what would one expect an organisation within the field's practice to be if it was influenced only by the logic of corporation, market, or religion, for example? Put differently, what are the 'sets of expectations' within the field connected to each of these logics?

Table 14.1 is an excerpt from Thornton et al.'s societal-level typology that shows the content of each cell according to the category 'Sources of Legitimacy'. This category identifies the key factor that gives the 
organisation legitimacy in any given context. Table 14.2 shows the content of each cell for the same category according to the field-level typology I developed.

While the field-level typology is closely related to the societal-level typology developed by Thornton et al. (2012), it can also include additional logics and categories that emerge as being of significance within the data collection process. For example, the logic of aid is a hybrid logic specific to the field that emerged as significant during my data collection, which involved both documentary analysis and interviews in a number of organisations within the field. To give another example, as shown in Table 14.3, 'Definition and determination of success' and 'Recruitment priorities' were found to play an important role in the everyday life of organisations within the field. Once I had developed the field-level typology, I then shared it with several of these organisations and adjusted it on the basis of my conversations with them.

\section{Researching Values in Practice}

Once a field-level typology of logics has been constructed, this can then be used as the lens through which organisational data is analysed. In this section, I draw on data from interviews conducted within one FBDO in the UK to demonstrate, firstly, how the institutional logics in action within organisational practice can be identified using the typology of logics; secondly, how the telos can be identified; and, lastly, how identifying the telos can enable one to study values in practice. It is important to emphasise that my own research is introduced within this section for illustrative purposes only rather than to present the findings, and therefore only certain elements of the analysis have been included.

Table 14.2 Field-level typology

\begin{tabular}{|c|c|c|c|c|c|}
\hline \multirow{2}{*}{$\begin{array}{l}\text { Y-axis } \\
\text { categories }\end{array}$} & \multicolumn{5}{|c|}{ X-axis institutional orders } \\
\hline & Corporation & Market & Religion & Community & Aid \\
\hline $\begin{array}{l}\text { Source of } \\
\text { legitimacy }\end{array}$ & $\begin{array}{l}\text { Status within } \\
\text { the sector }\end{array}$ & $\begin{array}{l}\text { The success and } \\
\text { marketability } \\
\text { of the product }\end{array}$ & $\begin{array}{l}\text { God's } \\
\text { call }\end{array}$ & $\begin{array}{l}\text { The needs of } \\
\text { the community }\end{array}$ & $\begin{array}{l}\text { The } \\
\text { cause }\end{array}$ \\
\hline
\end{tabular}




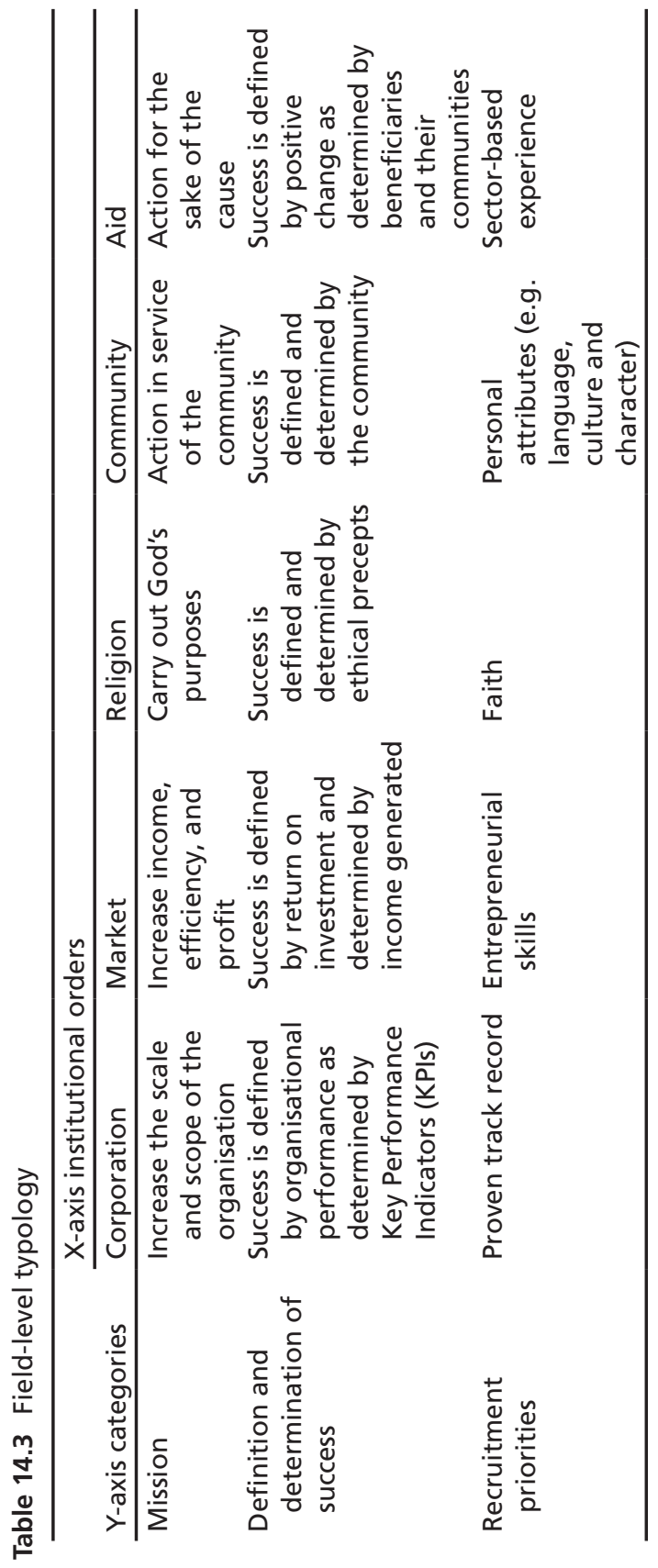




\section{Identifying Institutional Logics}

As noted above, the typology of logics was used as the lens through which to analyse the interview transcripts. I will show how the typology can be used in this way using the category 'Definition and determination of success' as depicted in Table 14.3. According to the logic of corporation, 'success is defined by organisational performance as determined by Key Performance Indicators (KPIs).' KPIs were frequently referred to in relation to measures of success within the organisation. I asked interviewees how they knew whether or not an aspect of their work had been successful, and although some discussed other measures of success, these were nearly always spoken of with reference to the KPIs. It quickly became apparent that KPIs were the key focus within organisational practice since they were the only aspect formally measured by the organisation. As one interviewee commented, for example, the organisation used KPIs for all the 'accountable' aspects of their work. Thus, in relation to this category the logic of corporation was clearly dominant at the organisational level.

Nevertheless, the typology enabled analysis of the action of other logics within organisational practice and, more specifically, at the individual level-that is, in relation to how employees negotiated organisationallevel logics. While interviewees clearly felt the pull of the logic of corporation in their work, this was also in tension with other logics. Speaking in relation to the staff they managed, one manager contrasted KPIs with 'personal' measures of success, which were not measured by the organisation. These measures of success included helping staff to deliver good quality work and also supporting them through personally challenging times. A tension became apparent through our conversation between the logic of corporation and those of religion and aid as far as 'success' was concerned. The source of this tension was that these personal measures of success were not captured by the manager's KPIs, but either contributed towards someone else's KPIs or were not measured at all. The manager explained, however, that this was where their faith enabled them to be humble and to keep in mind that, ultimately, they were carrying out their 
work for the sake of the people the organisation served rather than the organisation itself. Success for this interviewee personally was 'defined and determined by ethical precepts', as became apparent through the course of the interview. It was this that was the driving factor behind the time and effort they put into those aspects of their work not captured by the KPIs, enabling them to both keep the organisation's mission in mind — which they understood as being simultaneously about 'carrying out God's purposes' and 'action for the sake of the cause' - and accept the dominance of the corporate logic as far as the organisational-level conceptualisation of success was concerned.

Although what was measured by the organisation took primacy due to the overall dominance of the corporate logic in operation at the organisational level, then, interviewees also had their own individual-level measures of success related to other logics. Thus, using the typology as a lens through which to analyse data can illuminate the logics in action within organisational practice at both individual and organisational levels.

\section{Identifying the 'Telos'}

As discussed above, the 'telos' is an important category for researching values in practice. In relation to my data, the telos was identified through the process of coding the interview transcripts. The specific codes for the five logics were:

- 'telos is to build up and sustain the organisation' (logic of corporation)

- 'telos is capital' (logic of market)

- 'telos is to worship God' (logic of religion)

- 'telos is the common good' (logic of community)

- 'telos is social justice and relief' (logic of aid)

The process of coding the transcripts included identifying keywords, such as 'sustain', 'worship', or 'justice', and exploring the context in which these keywords were used and by whom. Words and phrases closely 
related to the keywords were also noted; for instance, 'serve God' or 'honour God' were identified in relation to the logic of religion. Once these portions of the transcripts had been assigned a code, it was then possible to look more closely at the data and ask questions of specific practices and scenarios that were highlighted in relation to these words-for example, what was this practice aiming towards, what was the expressed intention behind it, or what was the reason given as to why this scenario unfolded as it did?

One of the findings from the process of data analysis was that the dominant 'telos' within organisational practice was connected to that of the logic of corporation - that is, to 'build up and sustain the organisation' (see Table 14.4). This correlated with the overall dominance of the logic of corporation at the organisational level, in contrast to the individual level, where the operation of logics was more complex, with staff simultaneously negotiating multiple logics. Given the top-down nature of decision-making processes within the FBDO, it was not surprising that the code 'telos is to build up and sustain the organisation' most frequently occurred in interviews with those in higher-level roles across the organisation.

More specifically, the telos of the logic of corporation was most often referred to in the interviews as the 'long-term sustainability' of the organisation. The focus within the organisation did not seem to be so much about building up the organisation as sustaining it so that the work could continue into the future. What stood out within my data was not only the ways in which this 'telos' was guiding and influencing organisational practice, but also how and where it was interacting with other logics and impacting the values in practice within the organisation.

Table 14.4 Field-level typology

\begin{tabular}{|c|c|c|c|c|c|}
\hline \multirow{2}{*}{$\begin{array}{l}\text { Y-axis } \\
\text { categories }\end{array}$} & \multicolumn{5}{|c|}{ X-axis institutional orders } \\
\hline & Corporation & Market & Religion & Community & Aid \\
\hline Telos & $\begin{array}{l}\text { Build up and } \\
\text { sustain the } \\
\text { organisation }\end{array}$ & Capital & $\begin{array}{l}\text { Worship } \\
\text { God }\end{array}$ & $\begin{array}{l}\text { The common } \\
\text { good }\end{array}$ & $\begin{array}{l}\text { Social } \\
\text { justice } \\
\text { and relief }\end{array}$ \\
\hline
\end{tabular}




\section{Using the 'Telos' to Identify and Research Values in Practice}

Two of the explicit values held by individual staff members that emerged through the interviews were those of 'helping others' and 'serving others'. These were frequently mentioned in relation to the people the organisation worked with and were therefore arguably associated with the logic of aid. These values were also associated with the logic of religion for some, as the principal expressed motivation behind them was interviewees' faith in, and desire to serve, God. Yet the values tacit in organisational practice were not so easily identifiable within the data, and it was not until the telos of each logic in action within the organisation was identified that these began to emerge.

For instance, one interviewee commented that in order for the organisation to ensure its long-term sustainability, it needed to adopt a lot of the practices of 'well-run' organisations. Once the telos had been identified here, I then noticed its associated values, which included being a 'well-organised' and 'well-run' organisation, and 'developing staff. The data also showed that these values were seen by some interviewees as infringing on the values of 'helping others' and 'serving others' since, as one complained, 'there's not always an obvious link as to how this benefits those that you're trying to help'. This is a common dilemma in faithbased organisations (Espedal, 2019; Aadland \& Skjørshammer, 2012).

Another interviewee referenced the telos of the logic of corporation while underscoring the importance of 'financial viability', saying, 'it has to be financially viable otherwise we can't do it.' Referring to a decision that had to be taken to turn down a large grant because it did not cover the organisation's administrative costs, this interviewee explained that one of the difficulties when making decisions such as this is that the need to take a longer-term perspective can appear at odds with the value of 'helping others' that is so prevalent amongst staff. In this instance, the value of 'financial viability' was prioritised at the organisational level.

It is important to highlight that this approach enables analysis of the operation of values at multiple societal levels, which is an important aspect of values captured in Askeland et al.'s working definition (2020). 
For example, at the organisational level the telos of the logic of corporation and its associated values largely appeared compatible with the logic of religion. Although one of the most important aspects of work for interviewees in higher-level roles was that the organisation was sustained over the long term, for many this was because they saw the organisation as doing God's work. Therefore, in their view, God was being served through the work of the organisation. A similar point could be made in relation to the telos of the logic of aid, which is 'social justice and relief' for many, sustaining the organisation was the means by which this could be addressed. Thus, being well-run and financially viable were important values to uphold since they enabled the organisation to help and serve others.

However, at the individual level tensions emerged in practice in relation to how staff negotiated these values, especially when they were seen to be in competition with one another. For example, a tension emerged between the value of 'being a well-run organisation' and that of 'building a Christian ethos and culture' in relation to recruitment. It became apparent that certain roles within the organisation had a Genuine Occupational Requirement (GOR) for the post-holder to have an active Christian faith. There were specific criteria against which roles were assessed to see whether or not they had a GOR. This was found to be a source of tension: what decisions should be taken if in an interview process none of the candidates had an active faith in addition to the necessary technical skills to carry out the role? While recruitment processes can be rerun, this becomes increasingly difficult the more time and finances have been invested in the process. It emerged that managers prioritised differently in this regard, and several examples of unsuccessful recruitments along both lines were noted.

The dilemma faced by managers is that if the telos at the organisational level is to sustain the organisation in the long term, it contradicts this not to employ the most experienced candidate for a particular role or to restrict someone that has shown great aptitude and loyalty towards the organisation who wants to progress but does not meet the GOR for more senior positions. If the organisation is to be successful in a competitive environment, it needs employees who can get their work done and done well. This tension was felt all the more keenly in relation to recruitment 
in countries where the Christian community is in a minority and therefore the pool of suitable candidates that meet the GOR is limited.

These select examples illustrate how identifying the teloi of the institutional logics in action within organisational practice enabled me to research values in practice, not only bringing to light tacit values, but also highlighting their operation at multiple levels.

\section{Conclusion}

In summary, then, the perspective of institutional logics has the potential to make several important contributions to research on values in organisational practice. This is unsurprising given that a key assumption underlying the perspective is that value and practice are inseparable; however, while all institutional logics are value-based, some are more explicitly so than others. Thus, in this chapter I have shown that identifying the telos of each institutional logic in action within organisational practice, firstly, plays a critical role in unearthing the values tacit within such practice and, secondly, enables analysis of the operation of values at multiple levels, individual as well as collective.

\section{References}

Aadland, E., \& Skjørshammer, M. (2012). From God to good? Faith-based institutions in the secular society. Journal of Management, Spirituality \& Religion, 9(1), 83-101.

Askeland, H. (2020). Values - Reviewing the construct and drawing implications for values work in organisation and leadership. In H. Askeland, G. Espedal, B. J. Løvaas, \& S. Sirris (Eds.), Understanding values work (pp. 15-34). Palgrave Macmillan.

Espedal, G. (2019). Wide awake housekeepers on duty: The institutional logic of compassion in a faith-based organization. Nordic Journal of Religion and Society, 32(1), 22-39.

Friedland, R. (2009). The endless fields of Pierre Bourdieu. Organization, 16(6), 887-917. 
Friedland, R. (2012). Review of the institutional logics perspective: A new approach to culture, structure, and process.M@n@gement, 15(5), 582-595. Friedland, R. (2013). The gods of institutional life: Weber's value spheres and the practice of polytheism. Critical Research on Religion, 1(1), 15-24.

Friedland, R. (2017). The value of institutional logics. In G. Krücken, M. Carmelo, R. E. Meyer, \& P. Walgenbach (Eds.), New themes in institutional analysis (pp. 12-50). Edward Elgar Publishing.

Friedland, R. (2018). What good is practice?: Ontologies, teleologies and the problem of institution.M@n@gement, 21(4), 1357-1404.

Friedland, R., \& Alford, R. R. (1991). Bringing society back. In P. Symbols, I. Contradictions, I. W. W. Powell, \& P. J. DiMaggio (Eds.), The new institutionalism in organizational analysis (pp. 232-263). University of Chicago Press.

Gerhardt, U. (1994). The use of Weberian ideal-type methodology in qualitative data interpretation: An outline for ideal-type analysis. Bulletin of Sociological Methodology, 45, 74-126.

Goodrick, E., \& Reay, T. (2011). Constellations of institutional logics: Changes in the professional work of pharmacists. Work and Occupations, 38(3), 372-416.

Kraatz, M. S., Flores, R., \& Chandler, D. (2020). The value of values for institutional analysis. Academy of Management Annals, 14(2), 474-512.

North, D. C. (1990). Institutions, Institutional Change and Economic Performance. Cambridge University Press.

Reay, T., \& Jones, C. (2016). Qualitatively capturing institutional logics. Strategic Organization, 14(4), 441-454.

Scott, W. R. (2008). Institutions and Organizations: Ideas and Interests (3rd ed.). Sage Publications.

Swedberg, R. (2018). How to use Max Weber's ideal type in sociological analysis. Journal of Classical Sociology, 18(3), 181-196.

Thornton, P. H., \& Ocasio, W. (2008). Institutional logics. In R. Greenwood, C. Oliver, K. Sahlin, \& R. Suddaby (Eds.), The Sage handbook of organizational institutionalism (pp. 99-129). Sage Publications.

Thornton, P. H., Ocasio, W., \& Lounsbury, M. (2012). The institutional logics perspective: A new approach to culture, structure and process. Oxford University Press.

Weber, M. (1949). "Objectivity" in social science and social policy. In M. Weber (Ed.), Essays in the methodology of the social sciences (Trans. E. A. Shils \& H. A. Finch, pp. 50-112). The Free Press. 
Open Access This chapter is licensed under the terms of the Creative Commons Attribution 4.0 International License (http://creativecommons.org/licenses/ by/4.0/), which permits use, sharing, adaptation, distribution and reproduction in any medium or format, as long as you give appropriate credit to the original author(s) and the source, provide a link to the Creative Commons licence and indicate if changes were made.

The images or other third party material in this chapter are included in the chapter's Creative Commons licence, unless indicated otherwise in a credit line to the material. If material is not included in the chapter's Creative Commons licence and your intended use is not permitted by statutory regulation or exceeds the permitted use, you will need to obtain permission directly from the copyright holder.

(c) (1) 